\title{
Inhibition of Src activity enhances the tumor-suppressive effect of the connexin 32 gene in Caki-1 renal cancer cells
}

\author{
ERIKO FUJIMOTO ${ }^{1,2}$, HIROMI SATO $^{1,2}$, SUMIKO SHIRAI $^{1,3}$, YOJI NAGASHIMA ${ }^{3}$, NANTIGA VIRGONA $^{5}$, \\ KIYOKAZU HAGIWARA ${ }^{1}$, HIROSHI YAMASAKI ${ }^{5}$, ETSUKO NEGISHI $^{2}$, KOICHI UENO $^{2}$ and TOMOHIRO YANO ${ }^{1}$ \\ ${ }^{1}$ Department of Food Science Research for Health, National Institute of Health and Nutrition, Tokyo 162-8636; ${ }^{2}$ Graduate \\ School of Pharmaceutical Sciences, Chiba University, Chiba 260-8675; ${ }^{3}$ Department of Molecular Tumor Pathology, \\ Yokohama City University Medical School, Kanagawa 236-0004; ${ }^{4}$ Faculty of Sciences and Technology, Kwansei \\ Gakuin University, Hyogo 669-1337, Japan; ${ }^{5}$ Herbal Medicines Research and Education Centre, \\ Faculty of Pharmacy, The University of Sydney, NSW 2006, Australia
}

Received August 2, 2005; Accepted October 14, 2005

\begin{abstract}
Connexin (Cx) genes exert negative growth effects on tumor cells with certain cell specificity. We have recently reported that $\mathrm{Cx} 32$ acts as a tumor suppressor gene in a metastatic renal cancer cell line (Caki-1) due to the inactivation of Src. In line with the previous study, here we investigated if an Src family inhibitor (PP1) could enhance the tumor-suppressive effect of Cx32 in Caki-1 cells from human metastatic renal cell carcinoma. We examined the difference in the cytotoxic effect of PP1 on two cell clones, Cx32-transfected Caki-1 cells (Caki-1T) and mock-transfected Caki-1 cells (Caki-1W), in vitro as well as in vivo. PP1 showed more cytotoxic effect on Caki-1T than on Caki-1W at lower doses. This reinforcement was also observed in a xenograft model of nude mice. The in vitro reinforcement of the cytotoxic effect depended not only on control of cell-cycle transition but also on the induction of apoptosis, and the occurrence of the event was mostly caused by potential inhibition of Src activity in Caki-1T. Also, under a hypoxic condition, which is a typical environment of tumor tissue, Cx32 suppressed hypoxia-induced Src activation, and PP1 enhanced cytotoxicity in Caki-1T. These results suggest that, in addition to the Cx32-dependent tumor-suppressive effect, the concomitant inhibition of Src by PP1 is an effective procedure to induce a cytotoxic effect in Caki-1 cells.
\end{abstract}

\section{Introduction}

Renal cell carcinoma (RCC) is an adult-onset epithelial malignancy, accounting for approximately $85 \%$ of all kidney tumors with an estimated incidence of $>30000$ new cases per

Correspondence to: Dr Tomohiro Yano, Department of Food Science Research for Health, National Institute of Health and Nutrition, 1-23-1 Toyama, Shinjuku-ku, Tokyo 162-8636, Japan

E-mail: yano@nih.go.jp

Key words: connexin 32, renal cell carcinoma, Src, tumor suppressor gene, hypoxia year in the United States (1). RCC has a very poor prognosis, mainly because, in nearly $30 \%$ of all patients with localized disease, $40 \%$ of these ultimately develop distant metastases following removal of the primary tumor (1). Radical nephrectomy is the main treatment for localized RCC (1). However, radiotherapy and the available chemotherapeutic agents are ineffective against advanced and metastatic RCC (2). Furthermore, immunotherapy using interferon- $\alpha$ and interleukin-2 is effective in only a small percentage of patients with metastatic RCC and is extremely toxic (3). Therefore, the development of new therapies with an improved response in a large number of patients is clearly needed for the treatment of advanced and metastatic RCC.

Homeostasis in cellular society is one of the most important factors for maintenance of tissue function, and its disorder often results in dysfunction of organs and development of cancer (4). That is, the down-regulation of tumor suppressor genes keeping homeostasis during the carcinogenic process directly leads to the development of cancer. Among tumor suppressor genes contributing to tissue homeostasis, connexin (Cx) genes, a member of gap junction (GJ), are frequently down-regulated at an early stage of the carcinogenic process. Furthermore, the $\mathrm{Cx}$ gene preferentially exerts a tumorsuppressive effect on the tumor from normal cells in which the $\mathrm{Cx}$ gene is naturally expressed $(5,6)$. Thus, if we could determine the $\mathrm{Cx}$ gene specifically expressed in the progenitor cell of each tumor and clarify the tissue-specific tumor suppressive effect of the gene, we could use it to establish a new therapy against the cancer. In recent studies, we have shown that $\mathrm{Cx} 32$ prominently expresses in the normal human renal epithelial cell, a normal cell leading to the development of renal cell carcinoma by carcinogenic stimulation, while the down-regulation of $\mathrm{Cx} 32$ occurs in human RCC cell lines as well as cancerous regions of human kidneys $(7,8)$. Also, we have found that $\mathrm{Cx} 32$ exerts negative growth effects on RCC cell lines from human advanced and metastatic RCC (9). These reports suggest that $\mathrm{Cx} 32$ acts as a tumor suppressor gene against advanced and metastatic RCC.

The Src family of kinases (Src), which is a family of intracellular non-receptor tyrosine kinases, is widely expressed in 
tissue and appears to play an important role in the regulation of cell adhesion, cell growth, and differentiation (10). There has been increasing evidence that the activation or overexpression of Src contributes to invasion, angiogenesis, and chemoresistance in several types of cancer (11). We have also reported that Src is a key molecule for determining malignancy in RCC (12). These reports suggest that $\mathrm{Src}$ is a potential novel therapy target for most cancers, including RCC. Since Cx32-dependent tumor suppression in advanced and metastatic RCC cells is in part based on the inactivation of Src (9), it is hypothesized that, in addition to Cx32-dependent inhibition of Src, further suppression of the activity by pharmacological treatment may reinforce the $\mathrm{Cx}$-induced negative growth control of RCC. If so, this treatment approach may lead to establishment of a new therapy against RCC. In this context, the present study was undertaken to clarify the above possibility.

\section{Materials and methods}

Cell culture, construct and transfect. Caki-1, a representative human metastatic renal cell carcinoma cell line was obtained from ATCC (Rockville, MS, USA), and maintained in media. The culture conditions were as follows: the cells were cultured in McCoy's 5A medium (Invitrogen, San Diego, CA) supplemented with $10 \%$ fetal calf serum (FCS) and penicillinstreptomycin on standard plastic tissue culture dishes and incubated in an atmosphere of $95 \%$ air $/ 5 \% \mathrm{CO}_{2}$ at $37^{\circ} \mathrm{C}$. The human $\mathrm{Cx} 32$ cDNA insert containing the entire coding region (13) was subcloned into the expression vector pcDNA3 (Invitrogen) at the KpnI-BamHI site, and the sequence of construct pcDNA3-Cx32 was confirmed by DNA sequencing. Parental cells were transfected with either $3 \mu \mathrm{g}$ of $\mathrm{Cx} 32 \mathrm{cDNA}$ or empty pcDNA3 vector as a control using Gene Jamar Transfect Reagent (Stratagene, La Jolla, CA). After 48 h, the transfected cells were selected in culture medium containing $0.6 \mathrm{mg} / \mathrm{ml} \mathrm{G} 418$ (Sigma, St. Louis, MO) for 2 weeks. In order to avoid clonal variations by selection, we combined all of the surviving clones and used the combined clones to estimate the tumor-suppressive effects of Cx32 (9).

Src activity inhibitor. Since 4-amino-5-(4-methylphenyl)-(tbutyl)-pyrazolo [3,4-d]pyrimidine (PP1) has been established as a highly potent and selective inhibitor of Src family tyrosine kinases (14), we selected PP1 as the inhibitor of the kinases. PP1 (Biomol, Plymouth Meeting, PA, USA) dissolved in DMSO was added to culture medium at various doses up to 5 $\mu \mathrm{M}$ as the final concentration, while control was treated with DMSO only. PP3 (4-amino-7-phenyl)-pyrazolo[3,4-d] pyrimidine; Biomol) was used as a negative control to confirm the selective inhibition of Src by PP1.

Cell culture under a hypoxic condition. A hypoxic condition $\left(0.5 \% \mathrm{O}_{2}, 5 \% \mathrm{CO}_{2}\right)$ was created using an AnaeroPack system (Mitsubishi Gas Chemical Co. Inc., Tokyo, Japan). The cells were placed in an AnaeroPack Rectangular Jar with AnaeroPack for Cell, according to the manufacturer's instructions, and cultured for 24-48 h.

Assessment of cell viability. The cells were plated at $1 \times 10^{4}$ cells/plate in a microtiter plate, cultured in culture medium for
$24 \mathrm{~h}$, and treated with PP1 for $72 \mathrm{~h}$ at indicated doses. In the hypoxic condition case, PP1 treatment was carried out for $48 \mathrm{~h}$ at the indicated doses. Following treatment, cell proliferation assay was undertaken using a WST-1 assay kit (Quick Cell Proliferation Assay Kit; MBL, Nagoya, Japan), according to the manufacturer's instructions. In brief, $10 \mu 1$ of WST-1 reagent was added to each well, and the plate was incubated in an atmosphere of $95 \%$ air $/ 5 \% \mathrm{CO}_{2}$ at $37^{\circ} \mathrm{C}$ for $10 \mathrm{~min}$. After incubation, the optical density at $450 \mathrm{~nm}$ in each well was determined using a microplate reader (Atto, Osaka, Japan).

Cell-cycle analysis. The cells were plated at $2 \times 10^{5}$ cells/plate, cultured in culture medium for $24 \mathrm{~h}$, and treated with PP1 for $24 \mathrm{~h}$ at $0.1 \mu \mathrm{M}$. Then, the cells were fixed in $70 \%$ ethanol for $30 \mathrm{~min}$ at $4^{\circ} \mathrm{C}$ and incubated in PBS containing $0.05 \mathrm{mg} / \mathrm{ml}$ propidium iodide, $1 \mathrm{mM}$ EDTA, $0.1 \%$ Triton $\mathrm{X}-100$, and $1 \mathrm{mg} /$ $\mathrm{ml}$ RNase A for $30 \mathrm{~min}$ at room temperature. The cell suspension was then passed through a nylon mesh filter and analyzed on a Becton Dickinson FACScan.

Estimation of apoptosis. The cells were plated at $2 \times 10^{5}$ cells/ plate, cultured in culture medium for $24 \mathrm{~h}$, and treated with PP1 for $48 \mathrm{~h}$ at $0.1 \mu \mathrm{M}$. Then, the induction of apoptosis was estimated quantitatively. In order to perform the estimation, a sandwich enzyme immunoassay was conducted by cellular DNA fragmentation ELISA (Roche Diagonistics, Tokyo, Japan) according to the manufacturer's instructions, and caspase 3 activity was determined by caspase $3 / \mathrm{CPP} 32$ colorimetric assay kit (Biovision, Mountain View, CA, USA) according to the manufacturer's instructions.

Determination of Src activity. The cells were plated at $1 \times 10^{6}$ cells/plate, cultured in culture medium for $24 \mathrm{~h}$, and treated with PP1 for $24 \mathrm{~h}$ at $0.1 \mu \mathrm{M}$. Then, the cells were solubilized in lysis buffer (50 mM Tris-HCl, pH 7.5-30\% glycerol). The lysate was centrifuged at $10000 \mathrm{x}$ g for $10 \mathrm{~min}$, and the supernatant was used as an enzyme source to determine Src activity. The reaction mixture contained the enzyme source, $250 \mathrm{ng}$ poly $\left(\mathrm{Glu}_{4}\right.$-Tyr) peptide-biotin conjugate, $10 \mathrm{mM} \mathrm{MgCl}$, $1 \mathrm{mM} \mathrm{MnCl}_{2}, 1 \mathrm{mM}$ dithiothreitol, $200 \mu \mathrm{M}$ ATP, and $20 \mathrm{mM}$ Tris- $\mathrm{HCl}$ buffer ( $\mathrm{pH} 7.4$ ), and the reaction was performed at $37^{\circ} \mathrm{C}$ for $15 \mathrm{~min}$. After the reaction, Src activity was estimated by enzyme-linked immunosorbent assay (ELISA) using the Tyrosine Kinase Assay Kit chemiluminescent detection (Upstate, Charlottesville, VA, USA), according to the manufacturer's instructions.

Immunoblot analysis. The level of each molecule was estimated by immunoblot analysis using a specific antibody against each protein. In brief, the cells were lyzed in $1 \mathrm{ml}$ of ice-cold lysis buffer (50 mM Hepes, $\mathrm{pH} 7.5,150 \mathrm{mM} \mathrm{NaCl}$, $10 \%$ glycerol, 1 mM EDTA, 1\% Triton X-100, 10 mM ßglycerol phosphate, $0.1 \mathrm{mM}$ sodium vanadate, $1 \mathrm{mM} \mathrm{NaF}$, $10 \mu \mathrm{g} / \mathrm{ml}$ leupeptin, $10 \mu \mathrm{g} / \mathrm{ml}$ aprotinin, $50 \mu \mathrm{g} / \mathrm{ml} \mathrm{4-(2-}$ aminoethyl)-benzenesulfonyl fluoride hydrochloride, $1 \mathrm{mM}$ dithiothreitol fluoride hydrochloride, $1 \mathrm{mM}$ dithiothreitol). The lysates were separated on $10 \%$ SDS-PAGE, transferred to nitrocellulose membranes and subjected to immunoblotting using anti-Bcl-xL, -Bcl-2, -Bax, and - 3 -actin (BD Biosciences, San Jose, CA, USA) and anti-total and -phosphorylated Src 


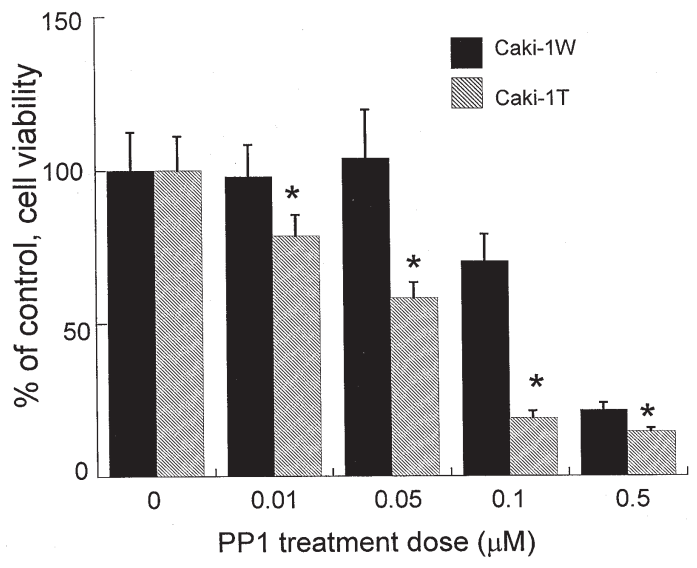

Figure 1. Dose dependency of PP1 in cell viability in Caki-1W and Caki-1T. The cells were treated with indicated concentrations of PP1 for $72 \mathrm{~h}$, and subsequent cell viability was determined using WST-1 reagent. Each value indicates the mean from six determinants; vertical lines indicate SEM. ${ }^{*}$ Significant difference from Caki-1W at each treatment dose. Caki-1W, mock-transfected Caki-1 cells; Caki-1T, Cx32-transfected Caki-1 cells.

(Upstate). Detection was accomplished using the ECL system (Amersham, Piscataway, NJ, USA) and a cooled CCD camera-linked Cool Saver System (Atto, Tokyo, Japan). A two-dimensional densitometric evaluation of each band was performed using ATTO Image Analysis Software (ATTO). Molecular sizing was performed using Rainbow Molecular Weight Marker (Amersham, Piscataway, NJ). Protein concentration was determined using DC Protein Assay (BioRad, Hercules, CA).

Tumorigenicity assay in nude mice. Aliquots of $1 \times 10^{7}$ cells of each cell group in MATRIGEL (BD Biosciences, Bedford, MA) were subcutaneously injected into the backs of five 5-week old BALB/c An-nu/nu athymic mice (Japan Clea, Tokyo, Japan). PP1 suspended in 50\% DMSO with PBS was administered intraperitoneally for tumor-bearing mice at $20 \mathrm{mg} / \mathrm{kg}$ on days $3,5,7,10,12,14,17$, and 19 after the injection of the tumor cells. On day 21 after the tumor cell injection, tumors were carefully removed after sacrifice and weighed. This experiment was carried out in five mice per group.

Statistical analysis. Data were analyzed by one-way analysis of variance followed by Dunnett's multiple-range test or Student's t-test. A P-value of 0.05 or less was considered significant.

\section{Results}

Effect of Src inhibition on cell viability in Caki-1W and Caki-1T. In a previous study, we have already established the Cx32-expressed Caki-1 cell (Caki-1T) and mock-transfected Caki-1 cell (Caki-1W) (9). The present study was carried out using the two established cell clones. Since we have found that the tumor-suppressive effect of Cx32 in Caki-1 cells partly depends on the inactivation of Src (9), we considered a possibility that further suppression of Src activity could reinforce the CX32-regulated negative growth control of the cancer cells. In order to examine this possibility, we determined
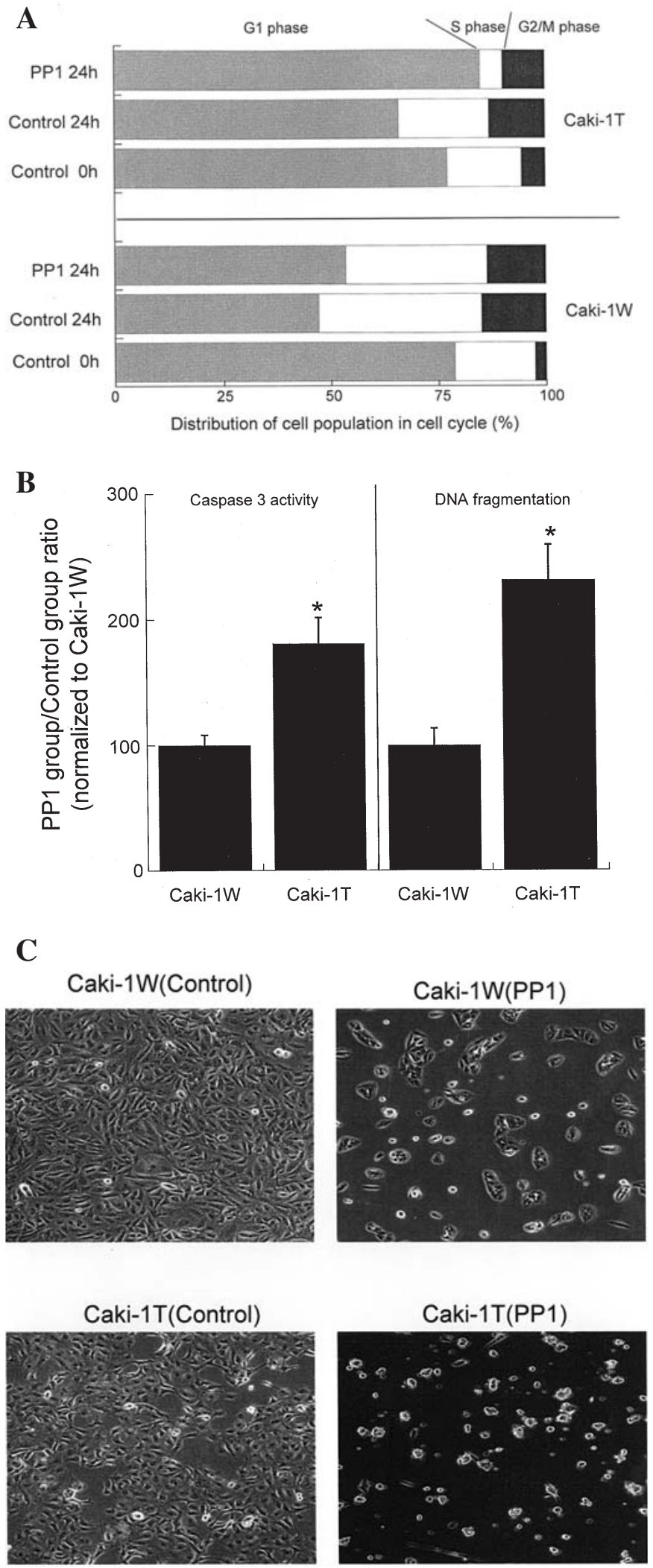

Figure 2. Cell-cycle progression (A), caspase 3 activity and DNA fragmentation (B), and morphological change (C) in Caki-1W and Caki-1T. A, the cells were treated with PP1 $(0.1 \mu \mathrm{M})$ for $24 \mathrm{~h}$. After the treatment, cell-cycle analysis was performed by FACS. Each value indicates the mean from three determinants. B, the cells were treated with PP1 $(0.1 \mu \mathrm{M})$ for $48 \mathrm{~h}$. After the treatment, each assay was carried out as described in 'Materials and methods'. Each value indicates the mean from five determinants; vertical lines indicate SEM. *Significant difference from Caki-1W. C, the cells were treated with PP1 $(0.1 \mu \mathrm{M})$ for $48 \mathrm{~h}$. After the treatment, the cells were observed by phase-contrast microscopy. Each morphological change is representative of three samples and magnification is $\mathrm{x} 100$. 
A

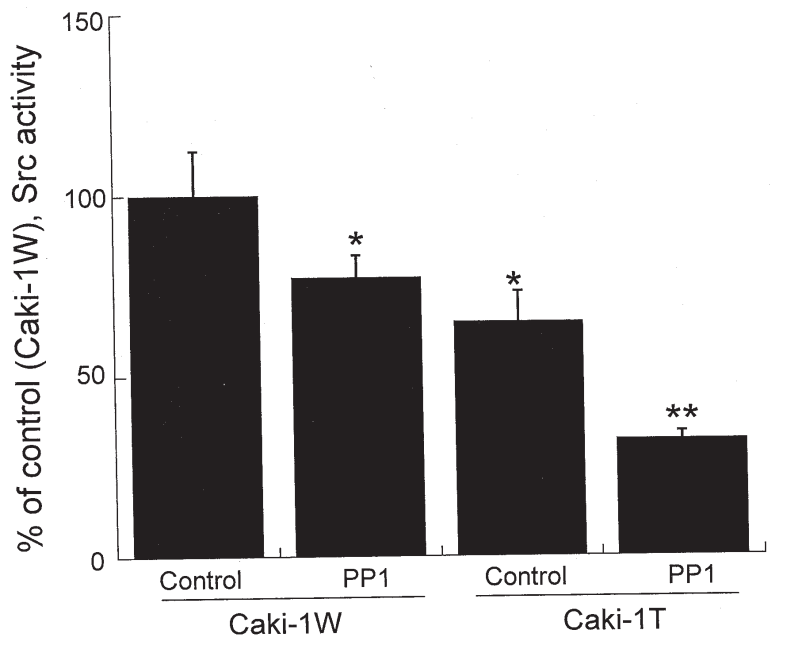

B

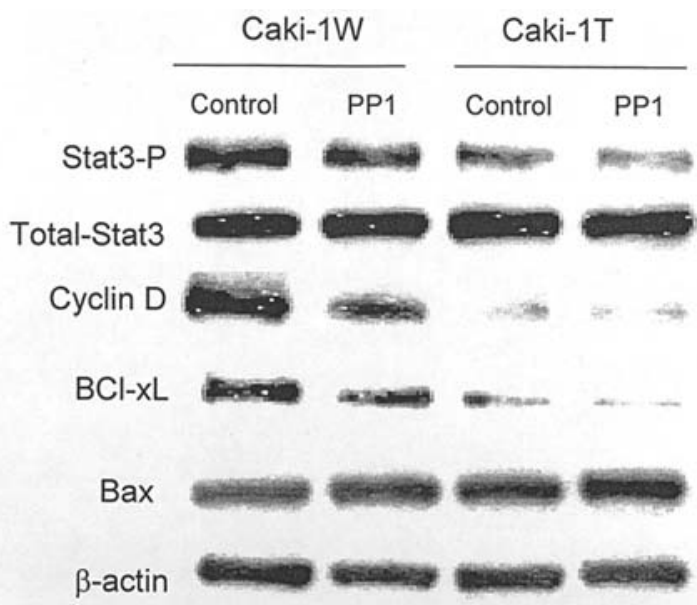

Figure 3. Effect of PP1 on Src activity (A) and Src-regulated signal molecules (B) in Caki-1W and Caki-1T. A, the cells were treated with PP1 $(0.1 \mu \mathrm{M})$ for $24 \mathrm{~h}$. After the treatment, Src activity was determined by ELISA as described in materials and methods. Each value indicates the mean from five determinants; vertical lines indicate SEM. *Significant difference from Caki-1W control; ${ }^{* *}$ Significant difference from other three groups. B, the cells were treated with PP1 $(0.1 \mu \mathrm{M})$ for $24 \mathrm{~h}$. After the treatment, levels of signal molecules were determined by immunoblot analysis. The results are representative of three independent experiments. Stat3-P shows the phosphorylated (active) form of Stat3.

the cytotoxic effect of an Src family inhibitor, PP1, on Caki-1T and Caki-1W. The dose dependency of the PP1-induced cytotoxicity against the two cells after $72 \mathrm{~h}$ exposure was examined, and the results are shown in Fig. 1. The PP1induced cytotoxicity against Caki-1T was more pronounced than that against Caki-1W in a dose-dependent manner. Under the same treatment conditions, we also confirmed that PP3, a structurally related molecule of PP1 which did not inhibit Src activity, had no cytotoxicity against the cancer cells (data not shown). Overall, it is suggested that the inhibition of Src activity enhances the negative growth control of $\mathrm{Cx} 32$ in Caki-1 cells.

Effect of Src inhibition on cell-cycle progression and induction of apoptosis in Caki-1W and Caki-1T. To distinguish if the observed difference in PP1-induced cytotoxicity resulted from cell-cycle arrest and/or induction of apoptosis, we performed both cell-cycle and apoptosis analysis. As shown in Fig. 2A,
A

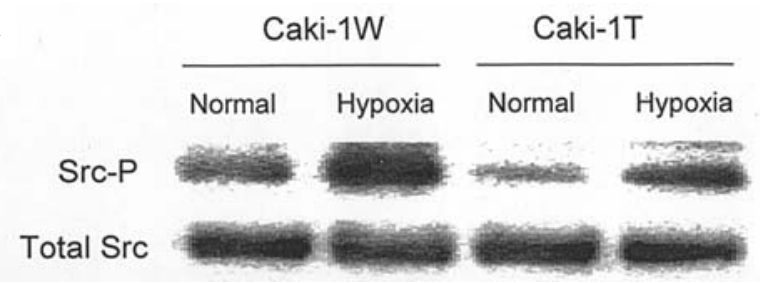

B

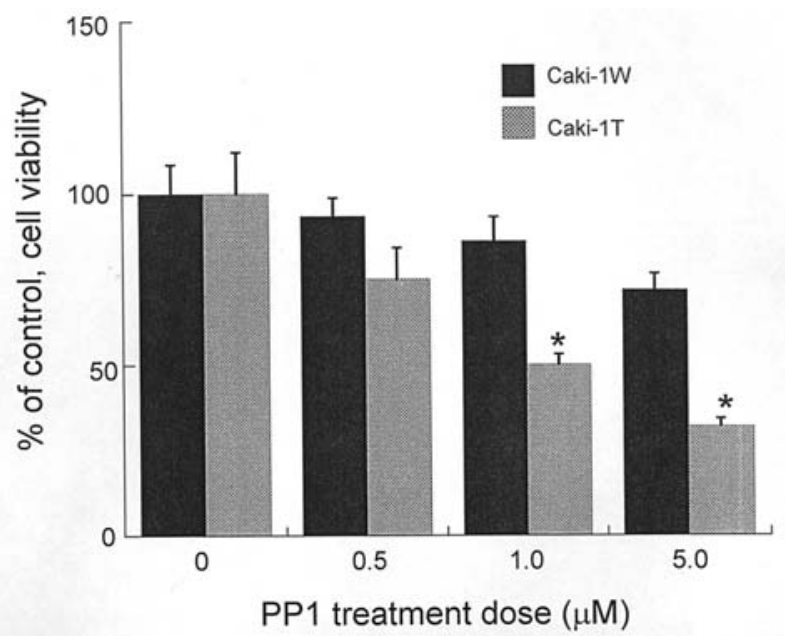

Figure 4. Effect of hypoxic treatment on Src activation (A) and PP1-induced cytotoxicity (B) in Caki-1W and Caki-1T. A, hypoxic treatment was carried out for $24 \mathrm{~h}$ as described in materials and methods, and the subsequent activation of Src was determined by immunoblot analysis. The results are representative of two independent experiments. The activated status of Src in each group was estimated by comparing the level of Src-P. Src-P shows the phosphorylated (active) form of Src. B, the hypoxic treatment was performed for $48 \mathrm{~h}$. After the treatment, cell viability was determined using WST-1 reagent. Each value indicates the mean from six determinants; vertical lines indicate SEM. *Significant difference from Caki-1W at each treatment dose.

Cx32 expression in Caki-1 cells caused G1 arrest in the cell cycle, and PP1 reinforced the Cx32-induced G1 arrest. Also, PP1-induced apoptosis in Caki-1 cells was enhanced by the expression of Cx32 with statistical significance (Fig. 2B) and was confirmed by microscopic observation (Fig. 2C). These results suggest that the enhancement of the PP1-induced cytotoxicity in Caki-1T depends not only on cell-cycle regulation but also on the induction of apoptosis.

Difference in Src activity and Src-regulated signaling between Caki-1W and Caki-1T. We have reported that Src activates signal pathways controlling cell survival as well as cell growth through the activation of signal transducer and activator 3 (Stat3) in RCC cells $(9,12)$. Therefore, in order to confirm a relationship between the activated status of Src/Stat3 signaling and the difference in PP1-induced cytotoxicity in Caki-1W and Caki-1T, we determined Src activity and levels of its regulated signal molecules. As shown in Fig. 3, Src activity, the activated status of Stat3, and the levels of a cell-cycle regulator (cyclin D), an anti-apoptotic molecule (Bcl-xL) and pro-apoptotic molecule (Bax) were closely associated with the difference in PP1-induced cytotoxicity in Caki-1W and Caki-1T. These results suggest that the difference in the activated status of Src signaling contributes strongly to the observed difference in PP1-induced cytotoxicity in Caki-1W and Caki-1T. 


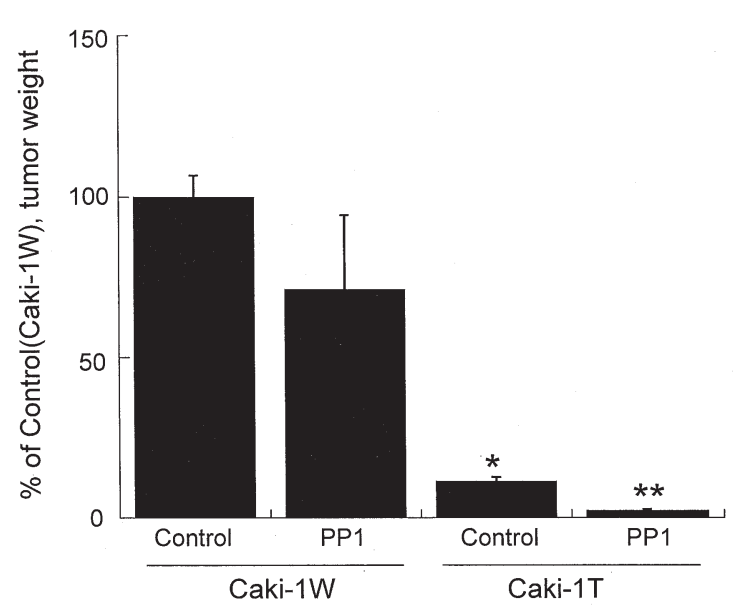

Figure 5. Effect of PP1 treatment on the development of Caki-1W and Caki-1T in nude mice. The injection of the cells, PP1 treatment and tumor measurement were performed as described in Materials and methods. Each value indicates the mean from five determinants; vertical lines indicate SEM. *Significant difference from control and PP1 treatment group in Caki-1W; ${ }^{* *}$ Significant difference from control in Caki-1W and Caki-1T, and PP1 treatment group in Caki-1W.

Effect of Src inhibition on cell viability in Caki-1W and Caki-1T under hypoxia. Reduction in tissue oxygen tension (hypoxia) is critical to the growth, invasion and metastasis of tumor cells, and the activation of Src by hypoxia is absolutely required to induce several molecules necessary for the survival and growth of tumor cells under hypoxia $(15,16)$. In this context, we examined whether there could be differences in Src activation and PP1-induced cytotoxicity between Caki-1W and Caki-1T under hypoxia. As shown in Fig. 4A, hypoxia-induced Src activation in Caki-1T was lower than that in Caki-1W, and the PP1-induced cytotoxicity against Caki-1T under hypoxia was much higher than that against Caki-1W in a dosedependent manner (Fig. 4B). These results suggest that, as with normal conditions, the inhibition of Src activity under hypoxia also enhances the $\mathrm{Cx} 32$-dependent negative growth control of Caki-1 cells.

Effect of Src inhibition on growth of Caki-1W and Caki-1T in a xenograft model with nude mice. To confirm that PP1 treatment reinforces the negative growth control of $\mathrm{Cx} 32$ in Caki- 1 cells in vivo, we examined whether the treatment could suppress the development of Caki-1T more effectively than that of Caki-1W in a xenograft model using nude mice. As previously reported (9), the development of Caki-1T was significantly less than that of Caki-1W, and PP1 treatment significantly suppressed the development of Caki-1T compared to the non-treatment (control) group of Caki-1T (Fig. 5). This result demonstrates that PP1 reinforces the tumor-suppressive effect of $\mathrm{Cx} 32$ in Caki-1 cells in vivo.

\section{Discussion}

It has been shown that the specific activity of Src is increased 5- to 8-fold in premalignant lesions and the majority of colorectal adenocarcinomas compared to normal colon tissue, and that the difference in Src activity is correlated with tumor progression (17). Moreover, a further increase of specific
Src activity is seen in cells derived from metastases versus cells from primary tumors (18). These reports indicate a stepwise increase in Src activity during various stages of tumor progression and its possible contributions to tumor development. We have also observed that Src activity in cells from metatastic RCC was higher than that in cells from primary RCC (12). Thus, Src is a promising therapy target for RCC as well as for other cancers.

We have recently reported that $\mathrm{Cx} 32$ acts as a tumor suppressor gene against RCC cells having malignant phenotypes related to progression and metastasis (9). The tumorsuppressive effect of Cx32 in RCC cells mainly depends on the suppression of Src activation, and this suppression leads to the inhibition of several Src-regulated survival and growth signaling molecules (9). However, Cx32 alone can only induce a cytostatic effect, not a cytotoxic effect, against RCC cells. Furthermore, severe inhibition of Src by its specific inhibitors effectively induces cytotoxicity in cancer cells with activated Src (12). Thus, it seems that, in addition to the Cx32-dependent regulation of Src, further inhibition of Src by other inhibitors could cause cytotoxicity in RCC cells. In this study, we examined this possibility.

As expected, we observed that PP1 effectively induced cytotoxicity in Caki-1T at lower doses than in Caki-1W. We also found that this reinforcement of PP1 on Cx32-dependent negative growth control in Caki-1T was associated with cell growth control (cell-cycle regulation) and the induction of apoptosis. Of the Src-regulated signal molecules, Stat 3 is considered a key molecule for induction of the Src-dependent malignancy in cancer cells, including $\operatorname{RCC}(12,19,20)$, and Stat 3 also participates in cell growth and survival through the induction of cyclin $\mathrm{D}$ required for $\mathrm{G} 1 / \mathrm{S}$ progression in the cell cycle and the increase of $\mathrm{Bcl}-\mathrm{xL}$ as a representative antiapoptotic molecule, respectively $(20,21)$. We have also observed that the activation of Stat 3 caused by Src directly induces cyclin D and Bcl-xl in Caki-1 cells (22). Thus, it is likely that PP1 potentiates the Cx32-dependent negative growth control in Caki-1T due to the suppression of Src/Stat3induced upregulation of cyclin D and Bcl-xL. We confirmed that the level of Src activity in each group was closely related to the activated status of Stat3, the levels of cyclin D and $\mathrm{Bcl}-\mathrm{xL}$. In addition to this event, we observed that the level of Bax in Caki-1T was elevated by PP1 treatment. In general, it is well known that apoptosis is modulated by a changing balance in anti-apoptotic molecules, such as Bcl-xL, and proapoptotic molecules, such as Bax (23), so the reduction in the ratio of $\mathrm{Bcl}-\mathrm{xL}$ to Bax may contribute to the enhancement of PP1-induced apoptosis in Caki-1T.

Although hypoxia is toxic to both tumor cells and normal cells, the tumor cells undergo genetic and adaptive changes that allow them to survive and proliferate in hypoxic environments, leading to aggressive tumor behavior (24). Hypoxic tumor cells are also considered to be resistant to most anti-cancer agents for several reasons: for example, hypoxia selects cells that have lost sensitivity to p53-mediated apoptosis, which might lessen the sensitivity to some anticancer agents (25). Thus, inhibition of hypoxic adaptation in tumor cells may contribute to effective negative growth control of tumor cells. In this study, we observed that Cx32 suppressed hypoxia-induced activation of Src in Caki-1 cells and that PP1 enhanced cyto- 
toxicity in Caki-1 cells under the Cx32-regulated suppression of hypoxic Src activation. These data suggest that hypoxiainduced Src activation is a key factor in the induced hypoxic adaptation of Caki-1 cells and that the potential inhibition of Src activation by the combination of an Src inhibitor (PP1) and $\mathrm{Cx} 32$ is an effective procedure for regulating the growth and survival of Caki-1 cells under hypoxia. This hypothesis was confirmed in the xenograft model.

It is known that all tumors must undergo angiogenesis or neovascularization in order to acquire nutrients for continued growth and metastatic spread under hypoxia (26). Vascular endothelial growth factor (VEGF) is the most important factor in inducing angiogenesis and is up-regulated by Src-Stat3 activation (27). We have also demonstrated that $\mathrm{Cx} 32$ alone reduces the development of Caki-1 cells in a xenograft model due to the inhibition of Src-Stat3-VEGF signaling (9). In this study, we again showed that Cx32 drastically suppressed the in vivo growth of Caki-1 cells, but the Cx32-dependent growth inhibition of Caki-1 cells in the xenograft model was much higher than the growth inhibition by PP1 treatment alone. This result indicates that, in addition to Src inhibition, Cx32 acts on other target molecules to induce a drastic growth inhibition of Caki-1 cells. As a possible mechanism, we can speculate that $\mathrm{Cx} 32$-induced restoration of cell-cell contact inhibition contributes in part to the in vivo growth control of Caki-1 cells, because $\mathrm{Cx} 32$ causes the re-expression of cadherin-6, a major molecule required for cell adhesion function in renal epithelial cells and the subsequent recovery of cell-cell contact function (9). Thus, it seems that the multi-suppressive effects of Cx32 against Caki-1 cells lead to in vivo cell growth suppression. Furthermore, we observed that $\mathrm{Cx} 32$ did not induce the death of Caki-1 cells either in vivo or in vitro (data not shown). However, in addition to the Cx32-dependent inhibition of Src, further inhibition by PP1 treatment could induce cell death in most of the Caki-1 cells in vivo (data not shown). Since our recent report has demonstrated that difference of Src activity in various types of RCC cells is critical to determine if Src inhibitors induce cytotoxic or cytostatic effects in cancer cells (12), severe inhibition of Src activity in Caki-1 cells by the combination of Cx32 and PP1 may cause effective cell death in vivo.

In addition to the Cx32-dependent tumor-suppressive effect, $\mathrm{Cx}$ has an advantage in establishing a new cancer therapy for RCC. In general, it is well established that Cx genes acts as tumor suppressor genes via GJ allowing the direct transfer of small cytoplasmic hydrophilic metabolites $\left(\mathrm{M}_{\mathrm{r}}<1500\right)$ between neighboring cells to maintain cellular homeostasis (28). In a recent report, it has been shown that, due to GJ-dependent cell coupling, individual dying bladder cancer cells can spread cell death signals into adjacent cells which then also die by apoptosis, and that the messenger molecules which pass through gap junctions to kill the cell are probably calcium ions (29). In another study, glioma cells that resisted apoptosis due to the overexpression of $\mathrm{Bcl}-2$ could, nevertheless, be killed when they were coupled via GJ with vulnerable non-transfected counterparts (30). From this report, it is assumed that the effective dose of anti-cancer agent against cancer cells is reduced due to the propagation of cell death signals from dying cells to surrounding living cells via GJ. We also observed that inhibition of GJ-dependent functions by a specific inhibitor against the functions (18-glycyrrhetinic acid) partly abrogated PP1-induced cytotoxicity in Caki-1T (data not shown). Therefore, the above GJ-dependent function may be effective in Caki-1 cells. Overall, the combination of the renal tumor-suppressive effect of Cx32 and Src inhibitors such as PP1 is a promising strategy to establish a potential new cancer therapy for advanced and metastatic RCC.

\section{Acknowledgements}

This study was supported by a research grant for Health Sciences Focusing on Drug Innovation from the Japan Health Sciences Foundation (KH21012).

\section{References}

1. Motzer RJ, Bander N and Nanus DM: Renal-cell carcinoma. N Engl J Med 335: 865-875, 1996.

2. Rabinovitch RA, Zelefsky MJ, Gaynor JJ and Fuks Z: Patterns of failure following surgical resection of renal cell carcinoma implications for adjuvant local and systematic therapy. J Clin Oncol 12: 206-212, 1994.

3. Neigrier S, Escudier B, Lasset C, Douillard JY, Savary J, Chevreau C, Ravaud A, Mercatello A, Peny J, Mousseau M, Philip T and Tursz T: Recombinant human interleukin-2, recombinant human interferon $\alpha-2 \mathrm{a}$, or both in metastatic renal-cell carcinoma. N Engl J Med 338: 1272-1278, 1998.

4. Mesnil M and Yamasaki H: Cell-cell communication and growth control of normal and cancer cells: evidence and hypothesis. Mol Carcinog 7: 14-17, 1993.

5. Yano T, Hernandez-Blazqueze FJ, Omori Y and Yamasaki H: Reduction of malignant phenotype of HepG2 is associated with the expression of connexin 26 but not connexin 32. Carcinogenesis 22: 1593-1600, 2001.

6. Mesnil M: Connexin and cancer. Biol Cell 94: 493-500, 2002.

7. Yano T, Ito F, Satoh H, Hagiwara K, Nakazawa H, Toma H and Yamasaki H: Tumor-suppressive effect of connexin 32 in renal cell carcinoma from hemodialysis patients. Kidney Int 63: 381, 2003.

8. Yano T, Ito F, Kobayashi K, Yonezawa Y, Suzuki K, Asano R, Hagiwara K, Nakazawa H, Toma $\mathrm{H}$ and Yamasaki H: Hypermethylation of the $\mathrm{CpG}$ island of connexin 32: a candidate tumor suppressor gene in renal cell carcinomas from hemodialysis patients. Cancer Lett 208: 137-142, 2004.

9. Fujimoto E, Sato H, Shirai S, Nagashima Y, Fukumoto K, Hagiwara H, Negishi E, Ueno K, Omori Y, Yamasaki H, Hagiwara $\mathrm{K}$ and Yano T: Connexin 32 as a tumor suppressor gene in a metastatic renal cell carcinoma cell line. Oncogene 24: 3684-3690, 2005.

10. Brown MT and Cooper JA: Regulation, substrates and functions of src. Biochem Biophys Acta 1287: 121-149, 1996.

11. Frame MC: Src in cancer: deregulation and consequences for cell behavior. Biochim Biophys Acta 1602: 114-130, 2002.

12. Yonezawa Y, Nagashima Y, Sato H, Virgona N, Fukumoto K, Shirai S, Hagiwara H, Seki T, Ariga T, Senba H, Suzuki K, Asano R, Hagiwara K and Yano T: Contribution of the Src family of kinases to the appearance of malignant phenotypes in renal cancer cells. Mol Carcinog 43: 188-197, 2005.

13. Kumar NM and Gilula NB: Cloning and characterization of human and rat liver cDNAs coding for a gap junction protein. $\mathbf{J}$ Cell Biol 103: 767-776, 1986.

14. Hanke JH, Gardner JP, Dow RL, Changelian PS, Brissette WH, Weringer EJ, Pollok BA and Connelly PA: Discovery of a novel, potent, and Src family-selective tyrosine kinase inhibitor. Study of Lck- and FynT-dependent T cell activation. J Biol Chem 271: 695-701, 1996.

15. Namiki A, Brogi E, Kearney M, Kim EA, Wu T, Couffinhal T, Varticovski L and Isner JM: Hypoxia induces vascular endothelial growth factor in cultured human endothelial cells. J Biol Chem 270: 31189-31195, 1995.

16. Ellis LM, Staley CA, Liu W, Fleming RY, Parikh NU, Bucana CD and Gallick GE: Down-regulation of vascular endothelial growth factor in a human colon carcinoma cell line transfected with an antisense expression vector specific for c-src. J Biol Chem 273: 1052-1057, 1998. 
17. Cartwright CA, Meisler AI and Eckhart W: Activation of the pp60c-src protein kinase is an early event in colonic carcinogenesis. Proc Natl Acad Sci USA 87: 558-562, 1990.

18. Termuhlen PM, Curley SA, Talamonti MS, Saboorian MH and Gallick GE: Site-specific differences in pp60c-src activity in human colorectal metastases. J Surg Res 54: 293-298, 1993.

19. Bromberg JF, Wreszczynska MH, Devgan G, Zhao Y, Pestell RG, Albanese C and Darnell JE Jr: STAT3 as an oncogene. Cell 98: 295-303, 1999.

20. Sinibaldi D, Wharton W, Turkson J, Bowman T, Pledger WJ and Jove R: Induction of p21WAF1/CIP1 and cyclin D1 expression by the Src oncoprotein in mouse fibroblasts: role of activated STAT3 signaling. Oncogene 19: 5419-5422, 2000

21. Catlett-Falcone R, Landowski TH, Oshino MM, Turkson J, Levitzki A, Savino R, Ciliberto G, Moscinski L, FernandezLuna JL, Nunez G, Dalton WS and Jove R: Constitutive activation of STAT3 signaling confers resistance to apoptosis in human U266 myeloma cells. Immunity 10: 105-115, 1999.

22. Sato H, Nagashima Y, Shirai S, Fukumoto K, Hagiwara H, Yamasaki H, Hagiwara K, Negishi E, Ueno K and Yano T: Combination effect of connexin32 gene function and chemotherapeutic agents against mestastatic renal cell carcinoma cells. Proc Am Assoc Cancer Res 46: 785, 2005.

23. Chao DT and Korsmeyer SJ: Bcl-2 family: regulators of cell death. Annu Rev Immunol 16: 395-419, 1998.
24. Harris AL: Hypoxia-A key regulatory factor in tumour growth. Nat Rev Cancer 2: 38-47, 2002.

25. Brown JM and Wilson WR: Exploiting tumour hypoxia in cancer treatment. Nat Rev Cancer 4: 437-447, 2004.

26. Hockel $M$ and Vaupel P: Tumor hypoxia: definitions and current clinical, biologic, and molecular aspects. J Natl Cancer Inst 93: 266-276, 2001.

27. Gray MJ, Zhang J, Ellis LM, Semenza GL, Evans DB, Watowich SS and Gallick GE: HIF-1alpha, STAT3, CBP/p300 and Ref-1/APE are components of a transcriptional complex that regulates Src-dependent hypoxia-induced expression of VEGF in pancreatic and prostate carcinomas. Oncogene 24: 3110-3120, 2005.

28. Simpson I, Rose B and Loweinstein WR: Size limit of molecule permeating the junctional membrane channels. Science 195: 294-296, 1977.

29. Krutovskikh VA, Piccoli C and Yamasaki H: Gap junction intercellular communication propagates cell death in cancerous cells. Oncogene 21: 1989-1999, 2002.

30. Lin JH, Weigel H, Cotrina, ML, Liu S, Bueno E, Hansen AJ, Hansen TW, Goldman S and Nedergard M: Gap-junctionmediated propagation and amplification of cell injury. Nat Neurosci 1: 494-500, 1998. 